\title{
Polymorphisms of the Glucocorticoid Receptor Gene and Adrenal Suppression in Patients with Chronic Obstructive Pulmonary Disease Treated with Glucocorticoids for Acute Exacerbations
}

Pradeesh Sivapalan ( $\sim$ pradeesh.sivapalan.02@regionh.dk)

Herlev and Gentofte Hospital, University of Copenhagen, Hellerup

Stina W. Borresen

Copenhagen University Hospital: Rigshospitalet

Josefin Eklöf

Herlev and Gentofte Hospital, University of Copenhagen

Marianne Klose

Copenhagen University Hospital: Rigshospitalet

\section{Freja S. Holm}

Herlev and Gentofte Hospital, University of Copenhagen

Ulla Feldt-Rasmussen

Copenhagen University Hospital: Rigshospitalet

\section{Maria Rossing}

Copenhagen University Hospital: Rigshospitalet

Niklas R. Jørgensen

Copenhagen University Hospital: Rigshospitalet

\section{Rasmus L. Marvig}

Copenhagen University Hospital: Rigshospitalet

\section{Mohamad Isam Saeed}

Herlev and Gentofte Hospital, University of Copenhagen

\section{Torgny Wilcke}

Herlev and Gentofte Hospital, University of Copenhagen

Niels Seersholm

Herlev and Gentofte Hospital, University of Copenhagen

\section{Alexander G. Mathioudakis}

University of Manchester, Manchester Academic Health Science Centre, 2: Manchester University NHS Foundation Trust

\section{Jørgen Vestbo}

Manchester University, Manchester Academic Health Science Centre, 2: Manchester University NHS Foundation Trust 
Jens-Ulrik Stæhr Jensen

Herlev and Gentofte Hospital, University of Copenhagen, 2: Faculty of Health Sciences, University of Copenhagen

\section{Research article}

Keywords: adrenal insufficiency, adverse effects, chronic obstructive pulmonary disease, COPD exacerbations, corticosteroids, exacerbations, gene polymorphisms, metabolic disorders, prednisolone, haplotypes

Posted Date: December 16th, 2020

DOl: https://doi.org/10.21203/rs.3.rs-126008/v1

License: (c) (1) This work is licensed under a Creative Commons Attribution 4.0 International License. Read Full License 


\section{Abstract}

Background: Single-nucleotide polymorphisms (SNPs) of the glucocorticoid receptor (GR) gene NR3C1 have been associated with an altered sensitivity to glucocorticoids (GC), and thus may affect the therapeutic effects of GCs. We investigated the prevalence of adrenal suppression after treatment with GCs and evaluated whether GR SNPs were associated with the risk of adrenal suppression and metabolic disorders in patients with chronic obstructive pulmonary disease (COPD).

Methods: In an observational prospective cohort study, we recruited 77 patients with severe COPD receiving five days GC treatment for an exacerbation of COPD. $49 \%$ of patients also received regular inhaled corticosteroids. Adrenal function was evaluated with a corticotropin test 30 days after the exacerbation. Patients were genotyped for Bcl1, N363S, ER22/23EK and 9 $\beta$ SNPs.

Results: The prevalence of adrenal suppression (corticotropin-stimulated plasma-cortisol $\leq 420 \mathrm{nmol} / \mathrm{L}$ ) 1 month after GC treatment was 4/77 (5\%). There was no correlation between high-sensitivity ( $p$-value 0.79 ) or low-sensitivity ( $p$-value 0.26 ) GR haplotypes and stimulated cortisol levels for COPD patients treated with GCs. There was no difference between adrenal suppression and metabolic disorders in COPD patients stratified for high vs. low GC-sensitivity GR haplotypes plus wild type ( $p$-value $>0.05$ ).

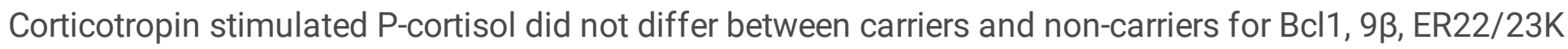
and N363S. For carriers of the high sensitivity GR gene haplotype, the association between inhaled corticosteroid dose and stimulated P-cortisol concentrations was more inverse (slope -0.25 vs. -0.10 ) than in patients with the low sensitivity haplotype.

Conclusions: Five percent of patients had an insufficient adrenal function. The Bcl1 and N363S polymorphisms do not seem to increase the risk of adrenal suppression or metabolic disorders in adults treated with corticosteroids for COPD exacerbations.

Trial Registration: The trial was registered at clinicaltrials.gov (NCT03140761) at May 4, 2017 with URL https://clinicaltrials.gov/ct2/show/NCT03140761.

\section{Background}

Systemic glucocorticoid (GC) therapy (30-40 mg prednisolone) is commonly used to treat patients for acute exacerbation of chronic obstructive pulmonary disease (COPD), irrespective of disease aetiology or phaenotype(1). This treatment is associated with several side effects $(2,3)$, including impaired endogenous GC production $(4,5)$ and severe psychological and somatic side effects $(6)$. Furthermore, short-term GC therapy was shown to suppress the hypothalamic-pituitary-adrenal (HPA) axis in 45-63\% of patients with COPD with exacerbation(4). The degree of adrenal cortex suppression caused by GC therapy varies considerably among individuals, and it is difficult to predict whether a particular patient will develop adrenal suppression or adrenal cortex failure(7, 8). Previous studies found no correlation between GC dose or therapy duration and the function of the HPA axis (5). 
The GC receptor (GR), encoded by the $N R 3 C 1$ gene, mediates the effects of GCs, and many polymorphisms in the GR gene have been associated with altered sensitivity to corticosteroids $(9,10)$. In patients with rheumatoid arthritis, four polymorphisms in the NR3C1 gene are clinically relevant. The polymorphisms N363S and Bcl1 are associated with increased corticosteroid sensitivity (i.e., highsensitivity GR gene haplotypes), and the polymorphisms ER22/23EK and $9 \beta$ are associated with decreased corticosteroid sensitivity (i.e., low-sensitivity GR gene haplotypes) (11).

Although the literature includes discrepancies, the first two haplotypes appear to be predictors of obesity, dyslipidaemia and hypertension (10). Bcl1 is associated with hyperglycaemia, increased insulin secretion and abdominal obesity (12). Furthermore, N363S has been found associated with the metabolic syndromes, type 2 diabetes mellitus and cardiovascular disease (13), whereas ER22/23EK and $9 \beta$ were associated with more favourable metabolic profiles (10). Increased prevalence of the $9 \beta$ polymorphism has been noted among patients with steroid-resistant asthma. However, the clinical significance of these polymorphisms for patients with COPD who undergo GC therapy is unknown.

To our knowledge, no study has investigated the association between GR haplotypes and adrenal suppression in patients with COPD following administration of GC. We assessed the prevalence of adrenal suppression after treatment with GCs and evaluated whether high GC-sensitivity haplotypes were associated with an increased risk of adrenal suppression and metabolic disorders in patients with COPD.

\section{Methods}

\subsection{Study design and patients}

This prospective population-based cohort study included 77 patients included 1 month after admission with COPD exacerbation (53\% females; median age, 75 years; range, $70-83$ years) at a large Respiratory Medicine department in Copenhagen, Denmark. Inclusion criteria were: (i) a diagnosis of COPD in a Caucasian aged 18 years or more; (ii) COPD exacerbation treated with GCs; and (iii) signed informed consent. Exclusion criteria were: (i) treatment with oestrogen-containing medication including contraceptives, less than 6 weeks before the corticotropin test; (ii) pregnancy or lactation; (iii) severe mental illness not adequately controlled by medication; (iv) detainment by law for psychiatric treatment; and (vi) permanent systemic GC therapy. We divided patients into high-sensitivity GR gene haplotypes (patients carrying Bcl1 and/or N363S, but not ER22/23EK and 9 $\beta$ ) and low-sensitivity GR gene haplotypes (patients carrying ER22/23EK and/or 9 3 , but not Bcl1 or N363S) plus wild type (patients wildtype for all 4 polymorphisms) respectively.

\subsection{Procedures}

All enrolled study patients were invited for a site visit 1 month after the acute exacerbation that included fasting venepuncture to measure fasting glucose, glycated haemoglobin levels, concentrations of the bone turnover markers $\mathrm{C}$-terminal telopeptide of type 1 collagen and procollagen type $1 \mathrm{~N}$-terminal propeptide, triglycerides, total cholesterol, as well as low-density and high-density lipoprotein cholesterol. 
DNA was extracted from peripheral venous blood samples using the QIAamp DNA mini kit (Qiagen, Hilden, Germany). DNA was genotyped for the four functional GR polymorphisms Bcl1, 9 $\beta, N 363 S$ and ER22/23EK. PCR reactions and genotyping procedures were carried out using the "allelic discrimination" technique, customised primers and probes, and the "Assay by Design service" provided by Applied Biosystems (Nieuwerkerk aan den IJssel, The Netherlands), in accordance with the manufacturer's instructions. Corticotropin tests were performed and blood samples collected 30 days after GC treatment for COPD exacerbation was completed. For all patients, weight, height, body mass index (BMI), systolic and diastolic blood pressure, waist and hip circumference were performed.

\subsection{Corticotropin test}

Adrenal cortisol secretion capacity was assessed using a short corticotropin test measuring the plasma cortisol concentration before and 30 min after intravenous administration of $250 \mu \mathrm{g}$ Synacthen ${ }^{\circledR}$ (synthetic adrenocorticotropic hormone). The threshold for diagnosing adrenal suppression using the short corticotropin test was based on adult reference concentrations (peak cortisol $\leq 420 \mathrm{nmol} / \mathrm{L}$ ) from the same laboratory and population $(14,15)$.

\subsection{Statistical analysis}

The power calculation was based on the haplotype analyses. We have made a t-test where the ratio between the groups was 3: 1 and where mean cortisol in the wild type plus ER22 / $23 E K$ and or $9 \beta$ was set to $469 \mathrm{nmol} / \mathrm{L}$ in corticotropin test vs. $369 \mathrm{nmol} / \mathrm{L}$ in the homo / heterozygous for the Bcl 1 and or N363S polymorphisms. Power was set to $80 \%$ and a type 1 error rate was $5 \%$. The test was made singlesided, as we did not expect the most sensitive group to respond better in the corticotropin test. Standard deviation was set to $137 \mathrm{nmol} / \mathrm{L}$. In this way we concluded that it was necessary to include 16 and 48 patients in each of the two groups respectively. A total of 64 patients. If we took into account that $20 \%$ of the recruited patients could not be placed in either of the two groups, we counted on recruiting an additional 13 patients. This meant that we had to recruit 77 patients to the study. Continuous data were expressed as means, standard deviations and interquartile ranges, whereas categorical variables were expressed as counts and percentages. Comparisons among groups were made using $t$-tests or MannWhitney $U$ tests for continuous variables and $\chi^{2}$ tests or Fisher's exact test when appropriate for categorical variables. For each genotype, the relationship between total systemic GC dose over the preceding 6 months and adrenal suppression was evaluated using linear regression models. Spearman's correlation was used to evaluate the correlation between high and low GR gene polymorphism and stimulated cortisol levels. Statistical analyses were carried out using SAS software (ver. 9.4; SAS Institute, Inc., Cary, NC, USA) and a $p$-value $<0.05$ was considered statistically significant.

\section{Results}

In total, 77 patients were included in the study. Overall, 4/77 (5\%) of patients had an insufficient response to the corticotropin test 1 month after treatment with corticosteroids. The most suppressed stimulated cortisol level was $280 \mathrm{nmol} / \mathrm{L}$. Two of the 38 patients with a Bcl1 or N363S genotype and none of the 12 
patients with ER22/23EK or $9 \beta$ genotype had adrenal suppression. SNP frequency was: N363S 3.9\%, Bcl1 $63.2 \%$, ER22/23EK $2.6 \%$ and $9 \beta 18.4 \%$. We found a negative association between male gender and stimulated cortisol response ( $\mathrm{Rho}=-0.24, p=0.042$ ), but no correlation to other possible confounders: $\mathrm{BMI}(\mathrm{Rho}=-0.15, p=0.22)$, age (Rho $=0.06, p=0.63)$, accumulated GC use 6 months before test (Rho $=$ $-0.14, p=0.23)$ and days since completed GCs (Rho $=0.09, p=0.47)$.

In the haplotype analyses, we included the 50 patients with either high- or low-sensitivity GR gene haplotypes or the wild-type GR haplotype (Table 1). In total, $46 \%$ of patients had hypertension, $6 \%$ had heart failure, $13 \%$ had diabetes and $3 \%$ had kidney disease. The baseline characteristics of the two groups were similar, except for ischaemic heart disease, which seemed more prevalent in the low plus wild type (25\%) than in the high (3\%) GC-sensitivity group. 
Table 1

Clinical and biochemical characteristics of COPD patients with high vs. low GC-sensitivity plus wild type haplotypes.

\begin{tabular}{|c|c|c|}
\hline & $\begin{array}{l}\text { Bcl1 or N363S } \\
(n=38)\end{array}$ & $\begin{array}{l}\text { ER22/23EK and } 9 \beta(n=12) \\
\text { plus wild type }\end{array}$ \\
\hline Age [years] & 74 (68 to 81$)$ & 75 (72 to 87$)$ \\
\hline Male (\%) & 44.7 & 54.5 \\
\hline Smoker (\%) & 31.6 & 9.1 \\
\hline Former smoker (\%) & 65.8 & 90.9 \\
\hline Never smoker (\%) & 2.6 & 0 \\
\hline Pack years & $45(32.5-60)$ & $48(35-54)$ \\
\hline Weekly alcohol consumption [units] & $1(0-7)$ & $1.5(0-7)$ \\
\hline Body mass index $\left[\mathrm{kg} / \mathrm{m}^{2}\right]$ & 25 (23 to 27$)$ & 26 (22 to 29$)$ \\
\hline \multicolumn{3}{|l|}{ Medication } \\
\hline Regular ICS (\%) & 50 & 67 \\
\hline Regular ICS daily dose $[\mu \mathrm{g}]$ & $\begin{array}{l}252(140 \text { to } \\
365)\end{array}$ & 400 (162 to 639$)$ \\
\hline $\begin{array}{l}\text { Days after last completed course of } \\
\text { corticosteroids }\end{array}$ & $28(22-32)$ & $28(26-31)$ \\
\hline $\begin{array}{l}\text { Accumulated systemic GC use } 6 \text { months before } \\
\text { corticotropin test [mg] }\end{array}$ & $\begin{array}{l}356(252 \text { to } \\
461)\end{array}$ & 264 (199 to 328$)$ \\
\hline LAMA (\%) & 76.3 & 91.7 \\
\hline LABA (\%) & 79.0 & 83.3 \\
\hline \multicolumn{3}{|l|}{ Comorbidity } \\
\hline Hypertension (\%) & 42.1 & 58.3 \\
\hline Atrial fibrillation (\%) & 13.2 & 16.7 \\
\hline Heart failure (\%) & 8.3 & 7.9 \\
\hline Kidney failure (\%) & 5.3 & 0 \\
\hline Diabetes mellitus (\%) & 18.4 & 8.3 \\
\hline
\end{tabular}

Data are expressed as medians (interquartile ranges) unless otherwise stated. GC: Glucocorticoids; LABA: Long-acting beta-agonist; LAMA: Long-acting muscarinic antagonist; ICS: Inhaled corticosteroids; COPD; chronic obstructive pulmonary disease; eGFR: Estimated glomerular filtration rate; PTH: Parathyroid hormone; TSH: Thyroid-stimulating hormone; ALAT: Alanine aminotransferase; ASAT: Aspartate transaminase; INR: International normalised ratio. 


\begin{tabular}{|c|c|c|}
\hline & $\begin{array}{l}\text { Bcl1 or N363S } \\
(n=38)\end{array}$ & $\begin{array}{l}\text { ER22/23EK and } 9 \beta(n=12) \\
\text { plus wild type }\end{array}$ \\
\hline Ischaemic heart disease (\%) & 2.6 & 25 \\
\hline Asthma (\%) & 13.2 & 0 \\
\hline \multicolumn{3}{|l|}{ Paraclinical parameters } \\
\hline Haemoglobin [mmol/L] & $\begin{array}{l}9.2(8.4 \text { to } \\
10.0)\end{array}$ & $8.9(8.4$ to 9.4$)$ \\
\hline Leucocytes [10E9/L] & 8.0 (7.3 to 8.8$)$ & $8.2(7.1$ to 9.4$)$ \\
\hline Thrombocytes [10E9/L] & $\begin{array}{l}303 \text { (270 to } \\
336)\end{array}$ & 296 (245 to 347$)$ \\
\hline Albumin [g/L] & $\begin{array}{l}42.8 \text { ( } 41.6 \text { to } \\
44.1)\end{array}$ & 41.4 (38.4 to 44.3$)$ \\
\hline Potassium [mmol/L] & 3.9 (3.8 to 4.0$)$ & 4.0 (3.7 to 4.2$)$ \\
\hline Sodium [mmol/L] & $\begin{array}{l}141.2(140.3 \text { to } \\
142.1)\end{array}$ & 139.9 (139.2 to 140.6$)$ \\
\hline Carbamide [mmol/L] & 5.8 (5.1 to 6.4$)$ & 7.4 (5.3 to 9.6$)$ \\
\hline Creatinine $[\mu \mathrm{mol} / \mathrm{L}]$ & $\begin{array}{l}78.1(71.1 \text { to } \\
85.0)\end{array}$ & 86.8 (75.6 to 98.0$)$ \\
\hline eGFR [mL/min] & $\begin{array}{l}73.5 \text { (68.4 to } \\
78.6)\end{array}$ & 66.1 (55.1 to 77.1$)$ \\
\hline ASAT [U/L] & $\begin{array}{l}34.7(29.0 \text { to } \\
40.4)\end{array}$ & 34.5 (25.7 to 43.4$)$ \\
\hline ALAT [U/L] & $\begin{array}{l}26.9(24.1 \text { to } \\
29.7)\end{array}$ & 25.2 (17.8 to 32.5$)$ \\
\hline Basic phosphatase [U/L] & $\begin{array}{l}75.4 \text { (69.1 to } \\
81.7)\end{array}$ & 72.3 (58.5 to 86.1 ) \\
\hline INR & $1.2(1.0$ to 1.3$)$ & $1.1(0.8$ to 1.5$)$ \\
\hline Fasting blood glucose [mmol/L] & $6.2(5.7$ to 6.6$)$ & 5.8 (5.4 to 6.2$)$ \\
\hline Corticotropin [pmol/L] & 4.9 (3.9 to 5.9$)$ & $4.3(1.5$ to 7.1$)$ \\
\hline Vitamin D [nmol/L] & $\begin{array}{l}78.9 \text { (70.3 to } \\
87.5)\end{array}$ & 80.4 (54.6 to 106.2$)$ \\
\hline PTH [pmol/L] & 6.7 (5.6 to 7.8$)$ & 9.6 (7.4 to 11.8$)$ \\
\hline \multicolumn{3}{|c|}{$\begin{array}{l}\text { Data are expressed as medians (interquartile ranges) unless otherwise stated. GC: Glucocorticoids; } \\
\text { LABA: Long-acting beta-agonist; LAMA: Long-acting muscarinic antagonist; ICS: Inhaled } \\
\text { corticosteroids; COPD; chronic obstructive pulmonary disease; eGFR: Estimated glomerular filtration } \\
\text { rate; PTH: Parathyroid hormone; TSH: Thyroid-stimulating hormone; ALAT: Alanine aminotransferase; } \\
\text { ASAT: Aspartate transaminase; INR: International normalised ratio. }\end{array}$} \\
\hline
\end{tabular}




\begin{tabular}{|c|c|c|}
\hline & $\begin{array}{l}\text { Bcl1 or N363S } \\
(n=38)\end{array}$ & $\begin{array}{l}\text { ER22/23EK and } 9 \beta(n=12) \\
\text { plus wild type }\end{array}$ \\
\hline $\mathrm{TSH}[\mathrm{U} / \mathrm{L}]$ & $1.7(1.3$ to 2.1$)$ & $1.9(0.18$ to 3.6$)$ \\
\hline \multicolumn{3}{|c|}{$\begin{array}{l}\text { Data are expressed as medians (interquartile ranges) unless otherwise stated. GC: Glucocorticoids; } \\
\text { LABA: Long-acting beta-agonist; LAMA: Long-acting muscarinic antagonist; ICS: Inhaled } \\
\text { corticosteroids; COPD; chronic obstructive pulmonary disease; eGFR: Estimated glomerular filtration } \\
\text { rate; PTH: Parathyroid hormone; TSH: Thyroid-stimulating hormone; ALAT: Alanine aminotransferase; } \\
\text { ASAT: Aspartate transaminase; INR: International normalised ratio. }\end{array}$} \\
\hline
\end{tabular}

There was no correlation between high ( $p$-value 0.79 ) or low sensitivity ( $p$-value 0.26$)$ GR gene haplotype and stimulated cortisol levels for COPD patients treated with GCs (Table 2, Fig. 1). Corticotropin stimulated P-cortisol did not differ between carriers and non-carriers of $\operatorname{Bcl} 1(p=0.74)$, 9-beta $(p=0.33)$, ER22/23K $(p=0.37)$ and N363S $(p=0.35)$ (Table 5).

\section{Table 2}

For carriers of the high sensitivity and low sensitivity GR gene haplotypes, the relationship between total systemic GC dose over the preceding 6 months and adrenal suppression was evaluated using Spearman's correlation

\begin{tabular}{|llll|}
\hline & Spearmans Rho & $95 \% \mathrm{Cl}$ & $P$-value \\
\hline Low sensitivity GR gene haplotype + wildtype $(\mathrm{n}=12)$ & -0.37 & $(-0.79$ to 0.31$)$ & 0.26 \\
\hline High sensitivity GR gene haplotype $(\mathrm{n}=38)$ & -0.05 & $(-0.36$ to 0.28$)$ & 0.79 \\
\hline Pooled $(\mathrm{n}=50)$ & -0.14 & $(-0.36$ to 0.09$)$ & 0.23 \\
\hline GR: Glucocorticoid receptor. & & & \\
\hline
\end{tabular}

For carriers of the high sensitivity GR gene haplotype, the association between inhaled corticosteroid (ICS) dose and stimulated P-cortisol concentrations was more inverse than in patients with the low sensitivity haplotype plus wild type (slope -0.25 vs. -0.10 , Table 3 , Fig. 2). 
Table 3

For carriers of the high sensitivity and low sensitivity plus wildtype GR gene haplotypes, the relationship between daily ICS dose and adrenal suppression was evaluated using linear regression models.

\begin{tabular}{|lccl|}
\hline & Slope & $95 \% \mathrm{Cl}$ & $P$-value \\
\hline Low sensitivity GR gene haplotype + wildtype $(\mathrm{n}=12)$ & -0.10 & $(-0.38$ to 0.17$)$ & 0.42 \\
\hline High sensitivity GR gene haplotype $(\mathrm{n}=38)$ & -0.25 & $(-0.38$ to -0.12$)$ & 0.0005 \\
\hline Interaction & & & 0.26 \\
\hline Pooled $(\mathrm{n}=50)$ & -0.21 & $(-0.32$ to -0.10$)$ & 0.0005 \\
\hline GR: Glucocorticoid receptor; GC: Glucocorticoids & & & \\
\hline
\end{tabular}

There was no difference between adrenal suppression and metabolic disorders in COPD patients stratified for high vs. low GC-sensitivity GR gene haplotypes plus wild type ( $p$-value $>0.05$, Table 4 ). 
Table 4

Adrenal suppression and metabolic disorders in COPD patients stratified for high vs. low GC-sensitivity GR gene haplotypes plus wild type.

\begin{tabular}{|c|c|c|c|c|}
\hline \multirow[t]{2}{*}{ Outcome } & \multirow{2}{*}{$\begin{array}{l}\text { Bcl1 or N363S ( } n= \\
\text { 38) } \\
\text { High-sensitivity GR } \\
\text { gene haplotypes }\end{array}$} & ER22/23EK and $9 \beta(n=12)$ & \multirow[t]{2}{*}{$\begin{array}{l}\text { Unadjusted } \\
p \text {-value* }\end{array}$} & \multirow[t]{2}{*}{$\begin{array}{l}\text { Pearson's } \\
\text { R }\end{array}$} \\
\hline & & $\begin{array}{l}\text { Low-sensitivity plus wild } \\
\text { type GR gene haplotypes }\end{array}$ & & \\
\hline $\begin{array}{l}\text { Basal cortisol } \\
\text { [nmol/L] }\end{array}$ & 362 (325 to 398$)$ & 307 (256 to 357$)$ & 0.12 & 0.22 \\
\hline $\begin{array}{l}\text { Stimulated } \\
\text { cortisol [nmol/L] }\end{array}$ & 675 (622 to 728$)$ & 655 (555 to 756$)$ & 0.71 & 0.06 \\
\hline $\begin{array}{l}\text { Adrenal } \\
\text { suppression (\%) }\end{array}$ & 5.4 & 0 & 0.43 & -0.11 \\
\hline $\begin{array}{l}\mathrm{HbA} 1 \mathrm{c} \\
{[\mathrm{mmol} / \mathrm{mol}]}\end{array}$ & 39.8 (37.4 to 42.3 ) & 40.0 (37.9 to 42.1$)$ & 0.94 & -0.01 \\
\hline P1NP [ $\mu \mathrm{g} / \mathrm{L}]$ & 39.5 (32.7 to 46.2 ) & 41.8 (28.8 to 54.8$)$ & 0.73 & -0.05 \\
\hline CTX [ng/L] & $\begin{array}{l}194.4(144.4 \text { to } \\
244.3)\end{array}$ & 247.4 (141.9 to 352.9$)$ & 0.31 & -0.05 \\
\hline $\begin{array}{l}\text { Systolic blood } \\
\text { pressure [mm Hg] }\end{array}$ & 137 (130 to 144 & 141 (127 to 155$)$ & 0.62 & -0.07 \\
\hline $\begin{array}{l}\text { Diastolic blood } \\
\text { pressure [mm Hg] }\end{array}$ & 78 (74 to 82$)$ & 77 (70 to 85) & 0.82 & 0.03 \\
\hline $\begin{array}{l}\text { Pulse [heart } \\
\text { rate/min] }\end{array}$ & 84 (78 to 90$)$ & 80 (71 to 88$)$ & 0.44 & 0.11 \\
\hline $\begin{array}{l}\text { Waist } \\
\text { measurement }[\mathrm{cm}]\end{array}$ & 97.6 (91.6 to 103.7 ) & 99.1 (90.3 to 107.9) & 0.81 & -0.04 \\
\hline $\begin{array}{l}\text { Hip measurement } \\
{[\mathrm{cm}]}\end{array}$ & 102.8 (98.5 to 107 ) & 102.3 (95.1 to 109.5 ) & 0.92 & 0.02 \\
\hline $\begin{array}{l}\text { HDL cholesterol } \\
{[\mathrm{mmol} / \mathrm{L}]}\end{array}$ & 1.6 (1.4 to 1.8$)$ & 1.3 (1.1 to 1.6$)$ & 0.15 & 0.21 \\
\hline $\begin{array}{l}\text { LDL cholesterol } \\
\text { [mmol/L] }\end{array}$ & 2.7 (2.4 to 3.1$)$ & 2.6 (2.2 to 3.0$)$ & 0.73 & 0.05 \\
\hline $\begin{array}{l}\text { VLDL cholesterol } \\
{[\mathrm{mmol} / \mathrm{L}]}\end{array}$ & 0.7 (0.6 to 0.9$)$ & 0.7 (0.5 to 0.9$)$ & 0.88 & 0.02 \\
\hline
\end{tabular}

Data are expressed as median (IQR) unless otherwise stated. HbA1c: glycated haemoglobin; P1NP: Procollagen type I N-terminal propeptide; CTX: C-terminal telopeptide of type 1 collagen; CAT: COPD assessment test; HDL: high-density lipoprotein; LDL: low-density lipoprotein; VLDL: very-low-density lipoprotein. *We planned to apply the Bonferroni correction. However, none of the $p$-values were significant. Therefore, we did not adjust for multiple testing. 


\begin{tabular}{|c|c|c|c|c|}
\hline \multirow[t]{2}{*}{ Outcome } & \multirow{2}{*}{$\begin{array}{l}\text { Bcl1 or N363S ( } n= \\
\text { 38) } \\
\text { High-sensitivity GR } \\
\text { gene haplotypes }\end{array}$} & & \multirow[t]{2}{*}{$\begin{array}{l}\text { Unadjusted } \\
p \text {-value* }\end{array}$} & \multirow[t]{2}{*}{$\begin{array}{l}\text { Pearson's } \\
\text { R }\end{array}$} \\
\hline & & $\begin{array}{l}\text { Low-sensitivity plus wild } \\
\text { type GR gene haplotypes }\end{array}$ & & \\
\hline $\begin{array}{l}\text { Triglycerides } \\
\text { [mmol/L] }\end{array}$ & 1.6 (1.3 to 1.9 ) & 1.6 (1.2 to 1.9 ) & 0.83 & 0.03 \\
\hline CAT score & 20.2 & 19.3 & 0.73 & 0.05 \\
\hline \multicolumn{5}{|c|}{$\begin{array}{l}\text { Data are expressed as median (IQR) unless otherwise stated. HbA1c: glycated haemoglobin; P1NP: } \\
\text { Procollagen type I N-terminal propeptide; CTX: C-terminal telopeptide of type } 1 \text { collagen; CAT: COPD } \\
\text { assessment test; HDL: high-density lipoprotein; LDL: low-density lipoprotein; VLDL: very-low-density } \\
\text { lipoprotein. *We planned to apply the Bonferroni correction. However, none of the } p \text {-values were } \\
\text { significant. Therefore, we did not adjust for multiple testing. }\end{array}$} \\
\hline
\end{tabular}

\section{Table 5}

Differences in stimulated P-cortisol for non-carrier vs. carrier haplotypes

\begin{tabular}{|llll|}
\hline & $\begin{array}{l}\text { Stimulated cortisol } \\
\text { Mean }(95 \% \mathrm{Cl})\end{array}$ & P-value & Pearson R \\
\hline Bcl1 & & \\
\hline Non-carrier & $654(606-702)$ & 0.74 & 0.04 \\
\hline Carrier & $666(609-724)$ & & \\
\hline $9 \beta$ & & & \\
\hline Non-carrier & $674(627-721)$ & 0.33 & -0.12 \\
\hline Carrier & $637(577-697)$ & & \\
\hline ER22/23EK & & 0.37 & -0.11 \\
\hline Non-carrier & $663(626-700)$ & & \\
\hline Carrier & $561($ not calculated, N $=2)$ & & \\
\hline N363S & & & \\
\hline Non-carrier & $651(612-689)$ & & \\
\hline Carrier & $708(617-799)$ & & \\
\hline
\end{tabular}

\section{Discussion}

In this study, we found that $5 \%$ of patients exhibited insufficient adrenal cortex function 30 days after undergoing treatment for COPD exacerbation with clear association with concomitant ICS dose. Compared with the ER22/23EK, $9 \beta$ and wildtype haplotypes, the Bcl1 and N363S haplotypes were not associated with an increased risk of adrenal suppression or metabolic disorders in patients with COPD 
exacerbation treated with GCs. In addition, there was no difference between stimulated cortisol concentrations of non-carriers vs. carriers for the 4 gene polymorphisms.

We have here determined the prevalence of adrenal suppression one month after exacerbation in a cohort of patients with severe COPD, of whom $49 \%$ received ICS treatment. We would expect a larger number of patients to be insufficient immediately after exacerbation. It was previously shown that several patients were insufficient soon after discontinuation of oral GCs but many regain adrenal function in the weeks and months after, and few remain insufficient for several years or for life (16). This patient group, with severe COPD must be at risk of repeated GC courses for exacerbations and thereby repeated episodes where the hypothalamic-pituitary-adrenal (HPA) axis is suppressed thereby resulting in a high risk of developing chronic adrenal insufficiency.

We did find a correlation between daily ICS dose and adrenal suppression (Fig. 2) for the high GR gene haplotype, although a greater proportion of patients in the low GR gene haplotype group plus wild type received ICS treatment.

Similarly, previous studies have found different genotypes associated with ICS-induced adrenal suppression in children with asthma(17-19). One of these studies, a genome-wide association study $(\mathrm{n}=$ 407) found that a common variant in the PDGFD locus was associated with an increased risk of adrenal suppression. Unlike our study, these analyses were performed in a cohort of children with less severe disease, and presumably they were treated with fewer rescue GC courses. Other genetic variants have been proposed relevant for GC sensitivity, but currently none have been introduced as a biomarker in routine clinical practice. Biomarkers predicting the risk of adrenal insufficiency in these patients might help clinicians to inform patients about the risk and train patients to recognize stressful situations (such as infection, trauma, or surgery) and the importance of additional GC supplements in these situations reduce the risk of adrenal crisis.

The effects of GCs on tissues are influenced by GC sensitivity, which is partly determined by functional single-nucleotide polymorphisms (SNPs) in the GR gene. Dexamethasone suppression testing has shown that the Bcl1 haplotype increases GC sensitivity in vivo (20), and this is correlated with increased $\mathrm{BMI}$ and central adiposity, as well as insulin resistance (21). Several SNPs in the GR gene influence sensitivity to GCs and have been linked with metabolic syndromes. However, the data include discrepancies, perhaps due to heterogeneity among the studied populations and the limited number of samples (13). GCs are used widely to treat a variety of lung diseases including COPD, asthma and interstitial lung diseases, and the effects of GC treatment vary considerably among patients. Some patients appear to respond well to GC therapy but also develop serious side effects. In contrast, other patients require very high GC doses to achieve clinical effects and do not exhibit side effects (22).

Previous studies have indicated a relationship between altered GC sensitivity mediated by the Bcl1 and ER22/23EK polymorphisms of the GR gene and changes in body composition and metabolism in healthy subjects $(20,22)$. However, in our study, we found no apparent difference between subjects with Bcl1 or N363S polymorphisms and those with ER22/23EK or $9 \beta$ polymorphisms and metabolic disorders. This 
may be due to differences in subject selection (i.e., healthy volunteers vs. COPD patients) and methodology. Another study found a correlation between the Bcl1 polymorphism and central adiposity, impaired glucose tolerance and dyslipidaemia in patients with Addison's disease (13). However, these results were obtained from a more heterogeneous study population than ours (i.e., including differences in disease duration, GC type and dose).

Most of the effects of GCs are probably mediated by the GR. However, the response to GCs varies considerably among individual subjects, which $\mathrm{s}$ is clear from the variation in the suppressive response to $0.25 \mathrm{mg}$ of dexamethasone. Several polymorphisms in the gene encoding the GR have been described. However, it is unclear to what extent the observed variations in response are due to GR polymorphisms or other factors.

A major strength of this study was that for the first time, we were able to study the association of GR haplotypes on adrenal suppression in COPD patients 1 month after the acute exacerbation treated with oral GCs on top of their usual treatment. It is important to determine this association since many COPD patients get frequent treatments with GCs. Moreover, our homogeneous patient population also included many comorbidities. Patients on permanent systemic GC therapy were not included because we were primarily interested in investigating the patients who received a short course of GCs for a COPD exacerbation. Also, ICS treatment was paused 24 hours before corticotropin test to avoid cross-reactivity with cortisol in the assay. All the cortisol analyses were performed in the same laboratory and with the same method as the earlier study(15). A major limitation of our study was that the number of patients that could be included in the comparison analysis was small. In small study populations like ours, there is a greater risk that any relationships observed are due to coincidence, and there is also a greater risk of overlooking a true association. However, significant associations between genetic polymorphisms and severe adverse drug reactions have previously been identified from small cohorts and led to changes in clinical practice (23). It has previously been shown that GR is involved in suppression of the HPA axis(24, 25). The most common causes of adrenal insufficiency are pituitary tumours, adrenal haemorrhage, infection and autoimmune disease(26). None of our patients were known to have any of these diseases. So, this is unlikely to have affected our results.

Unfortunately, we did not achieve the required number of patients with the prespecified haplotypes in each group, as suggested from the power analysis. Also, gathering low sensitivity GR gene haplotypes with wild type seems to be a limitation. Had we only included low sensitivity GR gene haplotypes, this would have required substantially more patients. We judged that including more patients was not necessary to examine our hypothesis. However, we acknowledge that grouping patients in low sensitivity and high sensitivity GR gene haplotypes and excluding patients with the wild type would have been more optimal. Furthermore, it is important to mention that our results need to be validated in future larger studies. In addition, the age group of the cohort selected for the study has many comorbidities that may be masking the effects of GR polymorphisms. Also, ex vivo models using reproduced alleles on plasmids may help understand whether the rationale is valid. 


\section{Conclusions}

Our findings suggest that the Bcl1 and N363S gene polymorphisms did not increase the risk of acute adrenal suppression in adults undergoing treatment with systemic GCs for COPD exacerbations. However, larger studies are needed to confirm this conclusion. Perhaps future studies applying whole-genome sequencing will identify other polymorphisms that may influence responses to GCs, including potential side effects.

\section{Abbreviations}

GC glucocorticoid

GR glucocorticoid receptor

COPD chronic obstructive pulmonary disease

ICS inhaled corticosteroids

SNP single-nucleotide polymorphism.

\section{Declarations}

Ethics approval and consent to participate: The study was approved by the Danish Committee on Health Research Ethics (H-15012207). All study procedures were carried out in accordance with the Declaration of Helsinki, and all participants provided written informed consent. The study was registered at clinicaltrials.gov (NCT03140761) before recruitment of patients.

Consent for publication: Not applicable.

Availability of data and materials: The datasets generated during and/or analysed during the current study are not publicly available but are available from the corresponding author on reasonable request.

Competing interests: All authors have completed the ICMJE uniform disclosure form, describing any conflicts of interest. None of the authors have any conflicts of interest that are directly related to this work.

Funding: This study was funded by the Danish Regions Medical Fund (5894/16), the Danish Council for Independent Research (6110-00268B) and Herlev-Gentofte University hospital. The research salary of PS was sponsored by Herlev and Gentofte Hospital, University of Copenhagen. The research salary of UFR was sponsored by an unrestricted research grant from the Novo Nordisk Fund. The research salary of SWB was sponsored by Skibsreder Per Henriksen, R. \& Hustru's Foundation; Eva Madura's Foundation; and The Research Foundation of Copenhagen University Hospital, Rigshospitalet. Alexander G. Mathioudakis and Jørgen Vestbo are supported by the National Institute for Health Research (NIHR) 
Manchester Biomedical Research Centre (BRC). The funders had no role in the design, data collection, analysis, interpretation of data and in writing the manuscript.

Author contributions: Conceptualisation, PS and JSJ; Formal analysis, PS; Funding acquisition, PS and JSJ; Investigation, PS, JE, FSH, SWB, MK and UF; Methodology, PS, SWB, MK, UF, MR, TW, NS, JV and JSJ; Project administration, PS and JSJ; Resources, PS, SWB, MK, UF, MR, NRJ, RLM and JSJ; Software, PS, JE and MIS; Supervision, JSJ; Validation, PS and JSJ; Visualisation, PS; Writing - original draft, PS; Writing - review \& editing, PS, SWB, JE, MK, FSH, UF, MR, NRJ, RLM, MIS, TW, NS, AGM, JV and JSJ. All authors have read and approved the manuscript.

Acknowledgements: We are grateful to the Steering Committee of COP:TRIN (coptrin.dk) for providing input to the study during meetings.

\section{References}

1. Singh D, Agusti A, Anzueto A, Barnes PJ, Bourbeau J, Celli BR, et al. Global Strategy for the Diagnosis, Management, and Prevention of Chronic Obstructive Lung Disease: The GOLD Science Committee Report 2019. Eur Respir J. 2019.

2. Walters JA, Tan DJ, White CJ, Gibson PG, Wood-Baker R, Walters EH. Systemic corticosteroids for acute exacerbations of chronic obstructive pulmonary disease. Cochrane Database Syst Rev. 2014(9):CD001288.

3. Sivapalan P, Ingebrigtsen TS, Rasmussen DB, Sorensen R, Rasmussen CM, Jensen CB, et al. COPD exacerbations: the impact of long versus short courses of oral corticosteroids on mortality and pneumonia: nationwide data on 67000 patients with COPD followed for 12 months. BMJ Open Respir Res. 2019;6(1):e000407.

4. Schuetz P, Leuppi JD, Bingisser R, Bodmer M, Briel M, Drescher T, et al. Prospective analysis of adrenal function in patients with acute exacerbations of COPD: the Reduction in the Use of Corticosteroids in Exacerbated COPD (REDUCE) trial. Eur J Endocrinol. 2015;173(1):19-27.

5. Henzen C, Suter A, Lerch E, Urbinelli R, Schorno XH, Briner VA. Suppression and recovery of adrenal response after short-term, high-dose glucocorticoid treatment. Lancet. 2000;355(9203):542-5.

6. McEvoy CE, Ensrud KE, Bender E, Genant HK, Yu W, Griffith JM, et al. Association between corticosteroid use and vertebral fractures in older men with chronic obstructive pulmonary disease. Am J Respir Crit Care Med. 1998;157(3 Pt 1):704-9.

7. Borresen SW, Thorgrimsen TB, Jensen B, Hilsted L, Bartels EM, Feldt-Rasmussen U, et al. Adrenal insufficiency in prednisolone-treated patients with polymyalgia rheumatica or giant cell arteritisprevalence and clinical approach. Rheumatology (Oxford). 2020.

8. Krasner AS. Glucocorticoid-induced adrenal insufficiency. JAMA. 1999;282(7):671-6.

9. Schwabe K, Vacca G, Duck R, Gillissen A. Glucocorticoid receptor gene polymorphisms and potential association to chronic obstructive pulmonary disease susceptibility and severity. Eur J Med Res. 
2009;14(Suppl 4):210-5.

10. Manenschijn L, van den Akker EL, Lamberts SW, van Rossum EF. Clinical features associated with glucocorticoid receptor polymorphisms. An overview. Ann N Y Acad Sci. 2009;1179:179-98.

11. van Oosten MJ, Dolhain RJ, Koper JW, van Rossum EF, Emonts M, Han KH, et al. Polymorphisms in the glucocorticoid receptor gene that modulate glucocorticoid sensitivity are associated with rheumatoid arthritis. Arthritis Res Ther. 2010;12(4):R159.

12. Rosmond R, Holm G. A 5-year follow-up study of 3 polymorphisms in the human glucocorticoid receptor gene in relation to obesity, hypertension, and diabetes. J Cardiometab Syndr. 2008;3(3):132-5.

13. Jewell CM, Katen KS, Barber LM, Cannon C, Garantziotis S, Cidlowski JA. Healthy glucocorticoid receptor N363S carriers dysregulate gene expression associated with metabolic syndrome. Am J Physiol Endocrinol Metab. 2016;311(4):E741-E8.

14. Klose M, Lange M, Rasmussen AK, Skakkebaek NE, Hilsted L, Haug E, et al. Factors influencing the adrenocorticotropin test: role of contemporary cortisol assays, body composition, and oral contraceptive agents. J Clin Endocrinol Metab. 2007;92(4):1326-33.

15. Klose MHL, Feldt-Rasmussen U. Method-specific serum cortisol responses to the ACTH test: comparison of two generations of Roche automated immunoassays using polyclonal vs MABs. European Society of Endocrinology. (Endocrine Abstracts (2016)):41 EP22.

16. Dinsen S, Baslund B, Klose M, Rasmussen AK, Friis-Hansen L, Hilsted L, et al. Why glucocorticoid withdrawal may sometimes be as dangerous as the treatment itself. Eur $\mathrm{J}$ Intern Med. 2013;24(8):714-20.

17. Hawcutt DB, Francis B, Carr DF, Jorgensen AL, Yin P, Wallin N, et al. Susceptibility to corticosteroidinduced adrenal suppression: a genome-wide association study. Lancet Respir Med. 2018;6(6):44250 .

18. Keskin O, Farzan N, Birben E, Akel H, Karaaslan C, Maitland-van der Zee AH, et al. Genetic associations of the response to inhaled corticosteroids in asthma: a systematic review. Clin Transl Allergy. 2019;9:2.

19. Keskin O, Uluca U, Birben E, Coskun Y, Ozkars MY, Keskin M, et al. Genetic associations of the response to inhaled corticosteroids in children during an asthma exacerbation. Pediatr Allergy Immunol. 2016;27(5):507-13.

20. van Rossum EF, Koper JW, van den Beld AW, Uitterlinden AG, Arp P, Ester W, et al. Identification of the Bcll polymorphism in the glucocorticoid receptor gene: association with sensitivity to glucocorticoids in vivo and body mass index. Clin Endocrinol (Oxf). 2003;59(5):585-92.

21. Geelen CC, van Greevenbroek MM, van Rossum EF, Schaper NC, Nijpels G, t Hart LM, et al. Bcll glucocorticoid receptor polymorphism is associated with greater body fatness: the Hoorn and CODAM studies. J Clin Endocrinol Metab. 2013;98(3):E595-9.

22. van Rossum EF, Lamberts SW. Polymorphisms in the glucocorticoid receptor gene and their associations with metabolic parameters and body composition. Recent Prog Horm Res. 
2004;59:333-57.

23. McCormack M, Alfirevic A, Bourgeois S, Farrell JJ, Kasperaviciute D, Carrington M, et al. HLA-A*3101 and carbamazepine-induced hypersensitivity reactions in Europeans. N Engl J Med. 2011;364(12):1134-43.

24. Nicolaides NC, Charmandari E, Chrousos GP, Kino T. Recent advances in the molecular mechanisms determining tissue sensitivity to glucocorticoids: novel mutations, circadian rhythm and ligandinduced repression of the human glucocorticoid receptor. BMC Endocr Disord. 2014;14:71.

25. Gjerstad JK, Lightman SL, Spiga F. Role of glucocorticoid negative feedback in the regulation of HPA axis pulsatility. Stress. 2018;21(5):403-16.

26. Bornstein SR. Predisposing factors for adrenal insufficiency. N Engl J Med. 2009;360(22):2328-39.

\section{Figures}

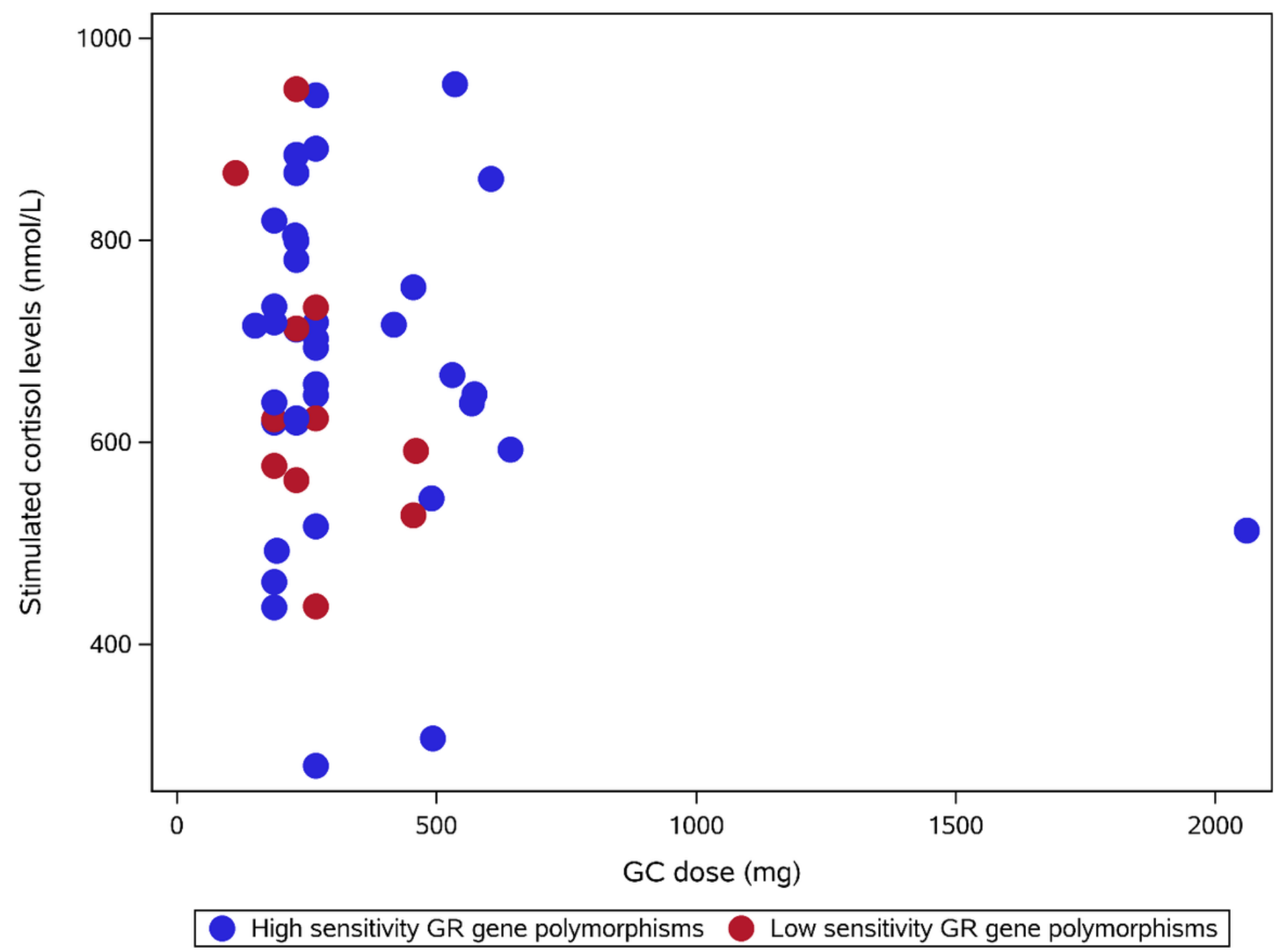

Figure 1 
The relationship between total accumulated systemic glucocorticoid dose (prednisolone equivalent dose, $\mathrm{mg}$ ) in the 6 months before the corticotropin test and stimulated cortisol concentrations for the highsensitivity glucocorticoid receptor gene haplotype group ( $p$-value 0.79 ) compared with the low-sensitivity and wild-type glucocorticoid receptor gene haplotype group ( $p$-value 0.26 ). Abbreviation: $G C=$ glucocorticoids; $\mathrm{GR}$ = glucocorticoid receptor.

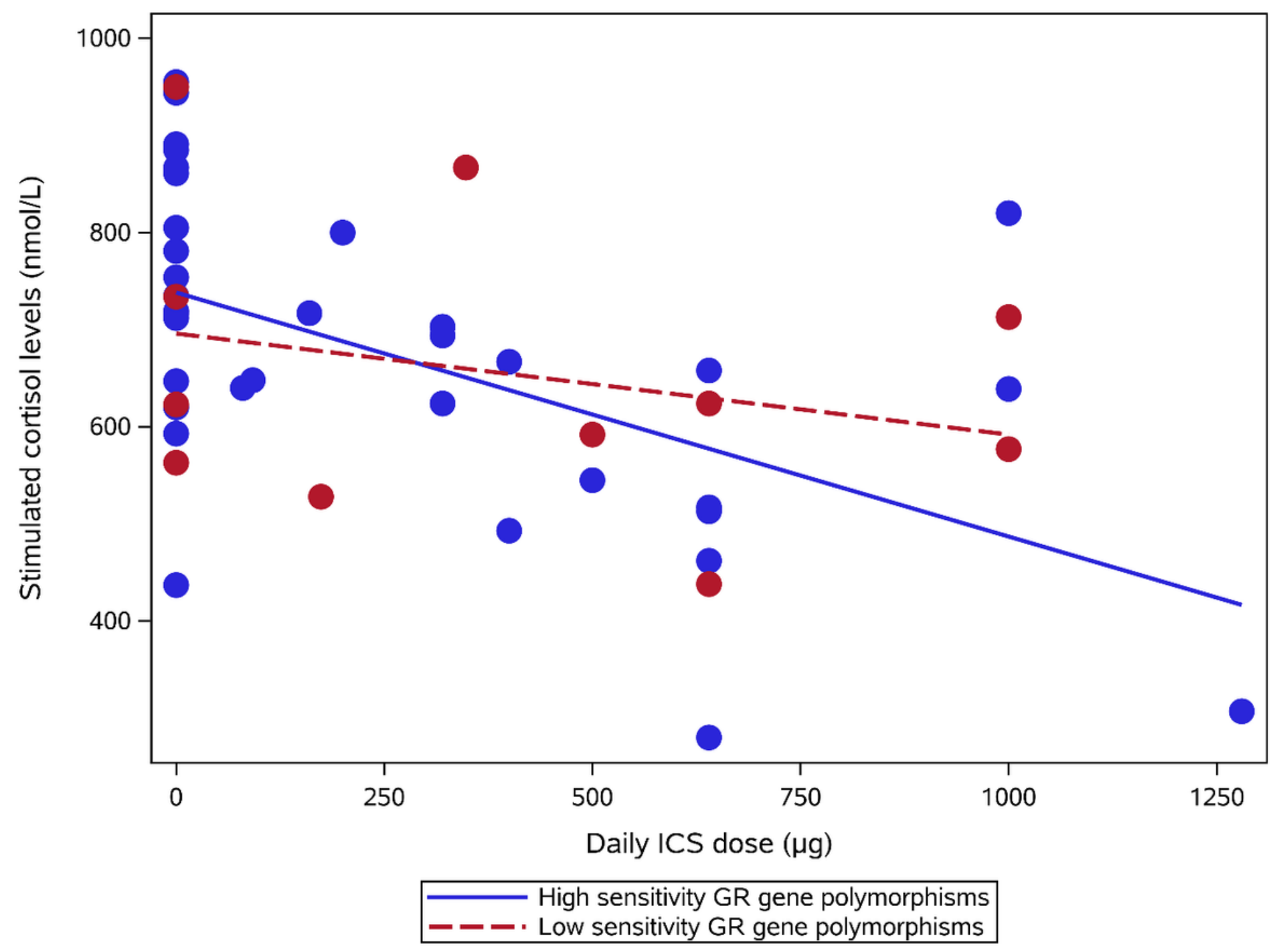

Figure 2

The relationship between ICS dose 1 day before the Corticotropin test $(\mu \mathrm{g})$ and stimulated cortisol concentrations at baseline for the high-sensitivity glucocorticoid receptor gene haplotype group compared with the low-sensitivity and wild-type glucocorticoid receptor gene haplotype group. Abbreviations: ICS = inhaled corticosteroid; GR = glucocorticoid receptor.

\section{Supplementary Files}

This is a list of supplementary files associated with this preprint. Click to download. 
- STROBEchecklistcohort.doc 